Maria de Lourdes dos Santos Souza

\title{
O Livro de Miquéias no conjunto dos Doze Profetas Estudo intertextual entre Mq 7,8-20 e os chamados Pequenos \\ Profetas
}

Tese apresentada como requisito parcial para obtenção do grau de Doutor pelo programa de Pósgraduação em Teologia Bíblica do Departamento de Teologia da PUC-Rio.

Profa. Maria de Lourdes Corrêa Lima

Orientadora

Departamento de Teologia - PUC - Rio

Rio de Janeiro

Outubro de 2006 


\title{
Maria de Lourdes dos Santos Souza
}

\section{O Livro de Miquéias no conjunto dos Doze Profetas Estudo intertextual entre Mq 7,8-20 e os chamados Pequenos Profetas}

\begin{abstract}
Tese apresentada como requisito parcial para obtenção do grau de Doutor pelo programa de Pós-graduação em Teologia Bíblica do Departamento de Teologia do Centro de Teologia e Ciências Humans da PUC-Rio. Aprovada pela comissão abaixo assinada.
\end{abstract}

Profa. Maria de Lourdes Corrêa Lima
Orientadora

Prof. Isidoro MAzzarolo

Departamento de Teologia - PUC - Rio

Prof. Ludovico Garmus

Departamento de Teologia - PUC - Rio

Prof. Nilson Faria dos Santos

Departamento de Teologia - PUC - Rio

Prof. Pedro Paulo Alves dos Santos Faculdade CCAA

Prof. Paulo Fernando Carneiro de Andrade Coordenador Setorial de Pós-Graduação e Pesquisa do Centro de

Teologia e Ciências Humanas - PUC-Rio

Rio de Janeiro, 
Todos os direitos reservados. É proibida a reprodução total ou parcial do trabalho sem autorização da universidade, do autor e do orientador

\section{Maria de Lourdes dos Santos Souza}

Graduou-se em Filosofia (Instituto Teológico Arquidiocesano Santo Antônio) em 1993 e em Teologia (Instituto Teológico Arquidiocesano Santo Antônio/PUC-Rio) em 1997. Concluiu o Mestrado em Teologia Bíblica / Puc-Rio em 2000.

Ficha Catalográfica

Souza, Maria de Lourdes dos Santos

O Livro de Miquéias no conjunto dos Doze Profetas: estudo intertextual entre $\mathrm{Mq} 7,8-20$ e os chamados Pequenos Profetas / Maria de Lourdes dos Santos Souza ; orientadora: Maria de Lourdes Corrêa Lima. - 2006.

286 f. ; $30 \mathrm{~cm}$

Tese (Doutorado em Teologia) - Pontifícia Universidade Católica do Rio de Janeiro, Rio de Janeiro, 2006.

Inclui bibliografia

1. Teologia - Teses. 2. Deus. 3. Amor. 4. Pastor. 5. Perdão. 6. Confiança. 7. Miquéias. 8. Livro dos Doze Profetas. 9. Intertextualidade. 10. Restauração de Sião. I. Lima, Maria de Lourdes Corrêa. II. Pontifícia Universidade Católica do Rio de Janeiro. Departamento de Teologia. III. Título.

CDD: 200 
À Rafaela, que no sofrimento me mostrou o caminho do amor, e à Fabiana que me sustentou com seu amor. 


\section{Agradecimentos}

A Deus, por ter me dado forças para superar as dificuldades e trilhado o seu caminho.

Ao Agenor, meu marido, pela paciência e compreensão em cada momento de nossa vida, principalmente neste projeto, que não teria se realizado sem o seu incentivo e amor.

À professora Doutora Maria de Lourdes Côrrea Lima, pela orientação competente e a confiança que proporcionou durante toda a elaboração deste trabalho.

À Graça, companheira fiel de tantos anos, e ao novo membro da família, Trajano, que com sua simplicidade e disponibilidade conquistou a todos nós.

A todos os professores do Departamento de Teologia da Puc-Rio, pelo carinho e atenção nestes anos de convívio.

A todos os amigos, que me ajudaram compreendendo as minhas necessidades e ausências.

Agradeço à Coordenação de Aperfeiçoamento de Pessoal de Nível Superior (CAPES) em virtude da Bolsa de estudos concedida. 


\section{Resumo}

Souza, Maria de Lourdes dos Santos; Lima, Maria de Lourdes Corrêa. Livro de Miquéias no conjunto dos Doze Profetas - Estudo intertextual entre Mq 7,8-20 e os chamados Pequenos Profetas, Rio de Janeiro 2006. 286 p. Tese de Doutorado, Departamento de Teologia - Pontifícia Universidade Católica do Rio de Janeiro.

Este estudo avalia a importância do livro de Miquéias no conjunto do livro dos Doze, privilegiando, o aspecto teológico. Nosso propósito é avaliar a interrelação do texto de Mq 7,8-20 com outros textos proféticos bem como a contribuição destes $\mathrm{O}$ propósito é examinar o texto final do livro de Miquéias, analisando a estrutura literária tramada com o propósito de encerrar o livro. As investigações atuais indicam que o horizonte dos escritos proféticos não se limita ao respectivo livro profético, mas que as complementações se estendem para além do livro. O título escolhido para este trabalho deve ser entendido sob esse aspecto. Dessa forma, além de lançar luzes sobre a polêmica acerca da unidade dos Doze Profetas, este estudo objetiva conhecer melhor o desenvolvimento, unidade e teologia dos Doze Profetas Menores, particularmente, o Livro de Miquéias.

\section{Palavras-chave}

Deus; amor; pastor; perdão; confiança; Miquéias; Livro dos Doze Profetas; intertextualidade; restauração de Sião. 


\section{Abstract}

Souza, Maria de Lourdes dos Santos; Lima, Maria de Lourdes Corrêa. The Book of Micah among the Twelve Prophets - na intertextual study between Mq 7, 8-20 and the so-called Minor Prophets, Rio de Janeiro 2006. 286 p. Doctor Degree Thesis, Department of Theology - Pontifícia Universidade Católica do Rio de Janeiro.

This research evaluates the role of the Book of Micah in the global structure of the Book of the Twelve, especially Micah’s theological aspect. Its purpose is to analyze the inter-relationship between the Book of Micah 7,8-20 and other prophetical texts, in an effort to determine how each of the prophets contributed with specific points for a greater interest. The purpose is to examine the final text of the Book of the Micah, evaluating how the literary structure was formed in order to conclude the Book. Present investigations indicate that the horizon of the prophetical scriptures is not limited to the respective prophetic Book, but that the complementary elements stretch out beyond the Book itself. The title of this work should be understood under this aspect. In this way, besides shedding light on the problematic of this unity of the Twelve Prophets, this work aims at better understanding of the development, the unit and the theology of the Twelve Minor Prophets, and particularly the Book of Micah.

\section{Keywords}

God; love; shepherd; forgiveness; faith; Micah; The Book of the Twelve; prophet; intertextuality; restauration of the Sion. 


\section{Sumário}

1. Introdução 14

2. A unidade do corpus profético do livro dos doze 21

2.1. Breve história das antigas evidências sobre a unidade dos Doze 21

2.2. A ordem dos livros 22

2.3. Atestações dos manuscritos antigos 29

2.4. Testemunhos bíblicos e extra-bíblicos 34

2.5. Status quaestionis sobre a unidade dos Doze -

Evolução da história da pesquisa dos Doze 39

2.5.1. Status quaestionis sobre a unidade dos Doze -

Evolução histórica da pesquisa dos Doze 40

2.5.2. O Livro dos Doze visto como uma Composição Redacional 42

2.5.3. Análise Crítica das propostas apresentadas pelo viés

da composição redacional 56

2.5.4. O Livro dos Doze visto como uma Compilação Literária 64

2.5.5. Análise Crítica das propostas apresentadas pelo viés da compilação literária $\quad 79$

3. Texto, constituição e organização 90

3.1. Tradução, notas filológicas e de crítica textual 90

3.2. Organização do texto de Mq 7,8-20 131

3.2.1. Delimitação 131

3.2.2. Constituição do texto 132

3.2.3. Estruturação do texto 135

3.3. Análise Semântica 138

4. Aproximações intertextuais entre Miquéias e os outros profetas 185

4.1 Análise das relações de Mq 7,8-20 com Na 1,2-8; 
4.1.1. O texto de $\mathrm{Na} 1,2-8$

4.1.2. Estudo da intertextualidade entre Miquéias e Naum

4.1.3. Averiguação literária entre os textos de Mq 7,8-20 e $\mathrm{Na} \mathrm{1,2-8}$

194

4.1.4. Análise do texto final de Naum = Na 3,15-17. 18-19 205

4.1.5. Análise da relação entre Abdias e Miquéias 216

4.1.6. Relação do Livro de Miquéias com o Livro de Jonas 221

4.1.7. Relação do livro de Miquéias com o Livro de Joel 226

5. Conclusão final 234

6. Referência Bibliográfica 244 


\section{Siglas e Abreviações}

Ab - Abdias

Ag - Ageu

Am - Amós

ANE - Ancient Near Eastern

AT - Antigo Testamento

AUSS - Andrews University Seminary Studies - Berrien Springs

BibInt - Biblical Interpretation - BRILL logo. Publisher:

BDB - The New Brown-Driver-Briggs-Gesenius Hebrew and English Lexicon, ed. F. Brown, Peabody, 1979

BHS - Biblia Hebraica Stuttgartensia, ed. K. Elliger - W. Rudolf, Stuttgart 1990 ${ }^{4}$, 1967/ 1977

BiKi - Bibel und Kirche

BN - Biblische Notizen - Münich, Alemanha

BTB - Biblical Theology Bulletin - St. John’s University, Jamaica NY

BZ - Biblische Zeitschrift - Paderborn, Alemanha

BZAW - Beiheft zur Zeitschrift für die alttestamentliche Wissenschaft

ca. - cerca

caps. - capítulos

CBQ - Catholic Biblical Quarterly

ColT- Collectanea Theologica, Warszawa - Poland

1-2 Cr - Primeiro e Segundo livro das Crônicas

CurTM - Currents in Theology and Mission - Chicago, IL

Dt - Deuteronômio

Dtr - Deuteronomístico

Ecl - Eclesiastes

Ed. - Editor - coordenador

ETL - Ephemerides Theologicae Lovanienses

EvQ - The Evangelical Quarterly - Birmingham, AL

EvT - Evangelische Theologie - Munique, Alemanha.

Ex - Êxodo

$\mathrm{Ez}$ - Ezequiel 
Gn - Gênesis

GTJ - Grace Theological Journal - Winona Lake, IN

Hab - Habacuc

HAR - Hebrew Annual Review

HTR - Havard Theological Review - Cambridge, MA

IBS - Irish Biblical Studies - Belfast - Irlanda

IEJ - Israel Exploration Journal - Jerusalem, Israel

Is - Isaías

ITQ - Irish Theological Quartely - Kildare, Ireland

JAOS - Journal of the American Oriental Society - New Haven, CT

JANES - Journal of the Ancient Near Eastern Society - New York

JBL - Journal of Biblical Literature - Scholar Press, Decatur

JETS - Journal of the Evangelical Theological Society - San Diego

$\mathrm{Jl}$ - Joel

Jn - Jonas

JNSL - Journal of Northwest Semitic Languages - South Africa

Jó - Jó

JQR - The Jewish Quarterly Review - PA

$\mathrm{Jr}$ - Jeremias

Js - Josué

JSJ - Journal for the Study of Judaism in the Persian, Hellenistic and Roman

Periods

JSNT - Journal for the Study of the New Testament

JSOT - Journal for the Study of the Old Testament - Sheffield. UK

JSS - Journal of Semitic Studies - The University of Manchester, Manchester,

JTS - Journal of Theological Studies - Oxford, UK

Jz - Juízes

KAT - Kommentar zum Alten Testament

Lm - Lamentações

Lv - Levítico

LXX - Septuaginta

Mq - Miquéias

$\mathrm{Ml}$ - Malaquias

$\mathrm{Na}$ - Naum 
$\mathrm{Ne}$ - Neemias

Nm - Números

NTT - Nederlands Theologisch Tijdschrift

OBO - Orbis biblicus et orientalis

Os - Oséias

p. - página

pp. - páginas

Pr - Provérbios

RDC - Revue de Droit Canonique

ResQ - Restoration Quarterly - Abilene, TX

RevQ - Revue de Qumran - Paris, França

Riv.Bibl. - Rivista Biblica - Mantova, Itália

RocTKan - Roczniki Teol.-Kanoniczne - Lublin, Polônia

1-2Rs - Primeiro e Segundo livro dos Reis

RTL - Reveu Théologique de Louvain - Louvain-la-Neuve, Bélgica

SBL - Society of Biblical Literature

Séc. - século

Sf - Sofonias

SJT - Scottish Journal of Theology - Edinburgh - Escócia

Sl - Salmos

1-2Sm - Primeiro e Segundo livro de Samuel

Syr - Peshita

Tg - Targum

TLZ- Theologische Literaturzeitung - Berlin, Alemanha

TM - Texto Massorético

v. - versículo

$\mathrm{Vg}$ - Vulgata

VT - Vetus Testamentum - Cambridge, UK

VTSupl- Vetus Testamentum Supplementum

Zc - Zacarias

ZAH - Zeitschrift für Althebraistik - Stuttgart, Alemanha

ZAW - Zeitschrift für die alttestamentliche Wissenschaft - Berlin, Alemanha

ZKTh - Zeitschrift für Katholische Theologie

ZLThK - Zeitschrift für die gesammte Lutherische. Theologie und Kirche 
“À alegria autêntica - e severa - vai consistir em nos dispormos, embarcados, ao serviço do ser. Este ofício é paixão e disciplina, perseverança $e$ esperança, modéstia - e embriagada lucidez. Cumpre arear, limpar, brunir, varrer, despojar-se, estar aberto, na viagem que fazemos. Cumpre doar a tudo o que existe o espaço indeterminado - e generoso - de nossa liberdade, para que nele tudo esplenda. Cumpre soletrar, com carinho, o nome das coisas e do Próximo, como um pastor que, no campo, pastoreia e abóia as reses do rebanho sob sua guarda." 